Original Research Article

\title{
A comparative study of impact on cognitive function between diabetic and non-diabetic patients in a tertiary care hospital
}

\author{
Dharnaben A. Patel*, Dhruv J. Patel, N. D. Kantharia
}

Department of Pharmacology, Government Medical College, Surat, Gujarat, India

Received: 18 May 2018

Accepted: 26 June 2018

\section{*Correspondence to:}

Dr. Dharnaben A. Patel, Email: p.dharna25@gmail.com

Copyright: (C) the author(s), publisher and licensee Medip Academy. This is an openaccess article distributed under the terms of the Creative Commons Attribution NonCommercial License, which permits unrestricted noncommercial use, distribution, and reproduction in any medium, provided the original work is properly cited.

\begin{abstract}
Background: Diabetes Mellitus is a chronic metabolic disorder characterized by hyperglycemia, polyuria, hyperlipidemia etc, resulting from defects in insulin secretion, insulin action or both. It affects various organs of the body including the brain. Cognitive function is the thinking process of the brain. In any chronic disease evaluation of cognitive function is justified as it may affect various common day to day activities.

Methods: It is a prospective, observational and non-interventional study. Thirty diabetic patients who were recently started on insulin i.e. within 7 days were enrolled in the study based on inclusion and exclusion criteria. Thirty non diabetic healthy individuals served as a control. Cognitive function was accessed by Adenbrooke's Cognitive Examination (ACE III) at the time of enrollment.

Results: The results were analysed using paired t-test. Attention, Memory and Visiospatial ability was significantly reduced in diabetic patients compared to control. Verbal fluency and language was also reduced but the change was not significant. Total ACE III score was significantly reduced in diabetic patients compared to control.

Conclusions: Cognitive function is significantly reduced in Diabetic patients recently started on insulin. Hyperglycemia could be the possible reason of cognitive decline. Proper understanding of the natural history of Diabetes and the pathogenesis of cognitive decline as well as control of Diabetes can help to prevent development of cognitive dysfunction.
\end{abstract}

Keywords: Adenbrooke's cognitive examination, Cognitive function, Diabetes mellitus

\section{INTRODUCTION}

Diabetes mellitus is a chronic metabolic disorder characterized by hyperglycemia, polyuria, hyperlipidemia etc. requiring life long care. It is very fast gaining the status of potential epidemic in India with more than 62 million diabetic individuals currently diagnosed with the disease. ${ }^{1}$ Also DM is the most challenging public health problem of 21 st century with a worldwide prevalence of 387 million (8.3\%) and predicted to be 592 million by $2035 .^{2}$ The chronic hyperglycemia of DM is due to various reasons such as environmental, genetic etc. Type $1 \mathrm{DM}$ is due to autoimmune destruction of the $\beta$-cells of the pancreas with consequent insulin deficiency whereas Type 2 is due to insulin resistance leading to reduced insulin sensitivity and therefore relative insulin insufficiency.

DM is a major cause of morbidity and mortality and is a major risk factor for early onset of coronary artery disease. Complications of DM are divided into macrovascular and microvascular. Macrovascular complications include coronary artery disease, peripheral arterial disease, and 
stroke whereas microvascular complications include diabetic nephropathy, neuropathy, and retinopathy. ${ }^{3}$

The word cognition comes from the Latin verb cognosco meaning 'I know, perceive' 'to conceptualize' or 'to recognize'. Cognition can be defined as all mental activities that are involved in acquisition, processing, storage and retrieval of information. In simple terms it is the thinking process of the brain and includes attention, learning, memory, verbal ability or language, visuospatial function, and a group of abilities, known as executive function i.e. reasoning, abstraction and mental flexibility. ${ }^{4}$

Cognitive decline is a less addressed complication of DM. Previous studies have shown a link between diabetes and mild cognitive impairment in persons with earlier onset and greater severity of diabetes. ${ }^{5,6}$ Considering the above fact, relationship between DM and cognitive function is complex. Thus this study was planned to access the impact of Diabetes on cognitive function, so that if any association between diabetes and cognition was found further studies can be carried out to see the impact of diabetes control on cognitive function.

\section{METHODS}

The study was observational and non-interventional. The study protocol was approved by Institutional Ethics Committee.

\section{Study subjects}

The study was conducted at New Civil Hospital Surat during the period of June 2015 to December 2015. The study was approved by the Institutional Ethics Committee. Informed consent was obtained from the participants.

Participants were divided into controls and cases. Controls $(n=30)$ consisted of age matched healthy non diabetic individuals of both gender. Cases $(n=30)$ consisted of diabetic patients of both gender who were recently started on insulin (i.e. within 7 days). Patients were enrolled from OPD's and IPD's of medicine department based on inclusion and exclusion criteria. DM was diagnosed by patients symptoms of diabetes plus random blood glucose concentration $11.1 \mathrm{mmol} / \mathrm{L}(200 \mathrm{mg} / \mathrm{dL})$ or fasting plasma glucose $7.0 \mathrm{mmol} / \mathrm{L}(126 \mathrm{mg} / \mathrm{dL})$ or 2 -hr plasma glucose $11.1 \mathrm{mmol} / \mathrm{L}(200 \mathrm{mg} / \mathrm{dL})$.

\section{Inclusion criteria}

Patients of Diabetes Mellitus who just started Insulin (i.e. within 7 days).

\section{Exclusion criteria}

- Patients not giving consent for enrollment in study.

- Patients taking drugs that are known to affect cognition such as Anticonvulsunts, Tricyclic
Antidepressants, Anticholinergics, Barbiturates, Benzodiazepines, Opiates

- Progressive neurological disorder,

- Head injury,

- Mental retardation,

- Drug and alcohol abuse,

- $\quad$ Severe Psychiatric problem.

A training session on cognitive function and how to fill up the Addenbrook's Cognitive Examination III form was conducted by department of psychiatry to the attending doctors. Cognitive function testing was done by Addenbrooke's Cognitive Examination III. The Addenbrooke's Cognitive Examination-III (ACE-III) is a brief cognitive test that assesses five cognitive domains: attention, memory, verbal fluency, language and visuospatial abilities.

After the taking the consent and basic details, participant is informed about the test and that he will be asked questions according to the Addenbrooke's scoring guide and cognitive function will be assessed. The participant is asked questions from Addenbrook's Cognitive Examination score sheet and scoring done accordingly as per the scoring guidelines. The Subjects were given participant information number which contained details of the subject, which were kept confidential.

\section{Statistical analysis}

The data were analysed using Microsoft Excel Professional Plus 2010. Data were expressed as mean \pm standard deviation. Student's $t$-test was used to assess statistical differences between the groups. $\mathrm{P}<0.05$ was considered statistically significant.

\section{RESULTS}

Thirty healthy non-diabetics were taken as control. (mean age was 53.10 $\pm 8.36 ; 17$ males, 13 females). Thirty confirmed cases of DM who were recently started on insulin were enrolled in the study.48.97 \pm 8.77 (mean age 48.97 $\pm 8.77,19$ males and 11 females) (Table 1).

Table 1: General characteristics of the study population.

\begin{tabular}{|lll|}
\hline Variable & Control & Case \\
\hline Age & $53.10 \pm 8.36$ & $48.97 \pm 8.77$ \\
\hline Gender & & \\
\hline Male & 17 & 19 \\
\hline Female & 13 & 11 \\
\hline FBS $(\mathrm{mg} / \mathrm{dL})$ & $105.39 \pm 11.18$ & $170.10 \pm 71.83$ \\
\hline PPBS $(\mathrm{mg} / \mathrm{dL})$ & $130.71 \pm 10.87$ & $238.65 \pm 87.46$ \\
\hline$\# \mathrm{p}<0.05$ vs. control group &
\end{tabular}

Fasting blood sugar (FBS) and postprandial blood sugar (PPBS) were $105.39 \pm 11.18 \mathrm{mg} / \mathrm{dL}$ and $130.71 \pm 10.87 \mathrm{mg} / \mathrm{dL}$ in the control group, respectively. 
FBS and PPBS were $170.10 \pm 71.83 \mathrm{mg} / \mathrm{dL}$ and $238.65 \pm 87.46 \mathrm{mg} / \mathrm{dL}$ in the before treatment group respectively (Table 1).

Table 2 shows the effect of DM on various domains of cognitive function. Attention: Before treatment with insulin i.e. in case group attention was significantly reduced to $14.35 \pm 2.23$ compared to $15.74 \pm 1.36$ in control group $(\mathrm{p}<0.05)$.

Table 2: Effect of diabetes on various domains of cognitive function.

\begin{tabular}{|lll|}
\hline Variable & Control & Case \\
\hline Attention & $15.74 \pm 1.36$ & $14.35 \pm 2.23$ \\
\hline Memory & $17.84 \pm 3.35$ & $13.68 \pm 4.61$ \\
\hline Fluency & $6.10 \pm 1.58$ & $5.77 \pm 2.28$ \\
\hline Language & $23.39 \pm 1.68$ & $22.55 \pm 2.35$ \\
\hline Visiospatial ability & $13.87 \pm 1.40$ & $12.90 \pm 2.51$ \\
\hline Total Score & $73.06 \pm 7.31$ & $65.39 \pm 11.92$ \\
\hline
\end{tabular}

\section{Memory}

In case group memory was significantly reduced to $13.68 \pm 4.61$ as compared to $17.84 \pm 3.35$ in control group $(\mathrm{p}<0.05)$.

\section{Fluency}

In case group fluency was reduced to $5.77 \pm 2.28$ as compared to $6.10 \pm 1.58$ in control group, but the change was not significant $(\mathrm{p}>0.05)$.

\section{Language}

In case group language was reduced to $22.55 \pm 2.35$ as compared to $23.39 \pm 1.68$ in control group, but the change was not significant $(\mathrm{p}>0.05)$.

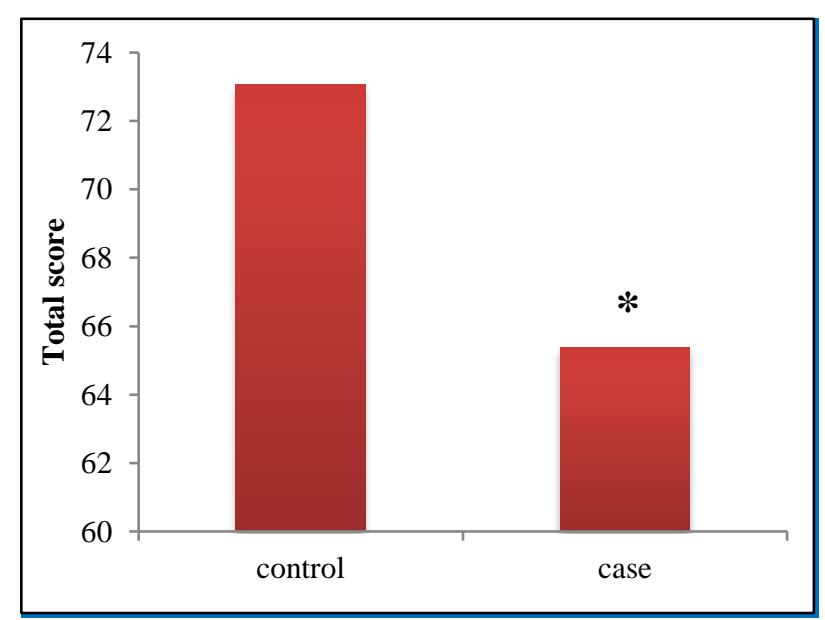

$* \mathrm{p}<0.05$

Figure 1: Effect of diabetes on cognitive function. Total score of ACE III was significantly reduced in case group compared to control group.

\section{Visiospatial ability}

In case group visiospatial ability was significantly reduced to $12.90 \pm 2.51$ as compared to $13.87 \pm 1.40$ in control group $(\mathrm{p}<0.05)$.

\section{Total score}

In case group visiospatial ability was significantly reduced to $65.39 \pm 11.92$ as compared to $73.06 \pm 7.31$ in control group $(\mathrm{p}<0.05)$.

\section{DISCUSSION}

Diabetes Mellitus is a major endocrine metabolic disorder affecting a vast population worldwide. It is responsible for significant mortality and morbidity due to its complications. Most of the vital organs are affected by DM including the brain. ${ }^{7}$ Cognitive dysfunction is a less addressed complication of DM. Diabetic patients have a greater rate of decline in cognitive function and exhibit approximately a 1.5-fold greater risk of accelerated cognitive decline and a 1.6-fold greater risk for the development of future dementia. ${ }^{8}$ Also cognitive impairment in DM patients may complicate adherence to medical regimens.

By keeping this in mind, this study was conducted to determine effect of DM on cognitive function. In this study cognitive function testing of controls and patients of diabetes mellitus (both type 1 and type 2) was done by Addenbrooke's Cognitive Examination III (ACE-III). Five domains of cognitive function were assessed by ACE III. Attention, memory, verbal fluency, language and visiospatial ability. At last total scoring of these five domains was done.

In this study, there was significant decrease in Attention, memory and visiospatial ability as compared to controls (normal healthy volunteers). Verbal fluency and language was also decreased but the change was not significant. Considering all this five domain total score of ACE III showed significant decrease as compared to control, suggesting some role of diabetes in decline of cognitive function.

Studies have shown mild to moderate decline in cognitive function in type $1 \mathrm{DM}$ characterized by a slowing of mental speed and a decreased mental flexibility, whereas learning and memory are spared. ${ }^{9}$ In type $2 \mathrm{DM}$ common cognitive deficits are decreases in processing speed and memory. ${ }^{10}$ However, one study did not find any differences in cognitive performance between type 1 and 2 DM, while vascular brain lesions were more prominent in the type $2 \mathrm{DM}$ group. The pattern of cognitive decline in type $1 \mathrm{DM}$ is generally similar to that found in type $1 \mathrm{DM}$. The marked difference is that type $2 \mathrm{DM}$ is associated with decreased memory and learning performance. ${ }^{11}$ 
Duration of diabetes, and coexistent microvascular and macrovascular complications are considered to be the main risk factors of cognitive impairment in diabetes. ${ }^{12}$ Hyperglycemia, vascular disease, hypoglycemia, and insulin resistance are the important pathophysiological aspects considered responsible for cognitive dysfunction in DM, but still mechanisms are unclear and further studies are needed to understand the mechanism responsible dor cognitive decline so that strategies can be developed for its prevention and treatment. ${ }^{13}$

An Australian study showed that people with chronically elevated fasting blood sugar showed marked hippocampal atrophy after 4 years. ${ }^{14}$ Hyperglycemia has also been proposed to cause end organ damage through increases in reactive oxygen species, in particular superoxide, which could then lead to increased polyol pathway activation, increased formation of AGEs, activation of protein kinase $\mathrm{C}$, and increased glucose shunting in the hexosamine pathway. ${ }^{15}$

Identification of the mechanisms through which DM may impair cognitive function will stimulate new research into ways to prevent and treat all the hyperglycemia-associated complications of diabetes. We can generate a hypothesis that early control of Diabetes with oral hypoglycemic agents or insulin can serve an important role in preventing this complication.

\section{CONCLUSION}

Cognitive function is significantly declined in DM. Cognitive dysfunction can be listed as one of the many complications of diabetes, along with retinopathy, neuropathy, nephropathy, and cardiovascular disease. In addition, understanding the natural history and identification of the mechanisms of cognitive decline in patients with DM will stimulate research to develop new and better ways to prevent and treat cognitive decline associated with DM.

\section{ACKNOWLEDGEMENTS}

Authors are thankful to Department of Medicine for their guidance and help.

Funding: No funding sources Conflict of interest: None declared

Ethical approval: The study was approved by the Institutional Ethics Committee

\section{REFERENCES}

1. Arshiya TNA. A Study of Frequency and Factors Associated with Depression among Adult Diabetics in Urban Areas of Davangere, Karnataka. National J of Comm Medic. 2016;7(2):111-5.
2. Kaveeshwar SA, Cornwall J. The current state of diabetes mellitus in India. The Australas Med J. 2014;7(1):45.

3. Michael J. Fowler M. Microvascular and Macrovascular Complications of Diabetes. American Diabetes Association Clinical Diabetes. 2008;26(2):77-82.

4. Mittal S, Verma P, Jain N, Khatter S, Juyal A. Gender based variation in cognitive functions in adolescent subjects. Annals of neurosciences. 2012 Oct;19(4):165.

5. Caputo JB, Vagula MC. Cognitive impairment and dementia in Type 2 diabetes mellitus. US Pharm. 2014;39(10):33-7.

6. Feinkohl I, Price JF, Strachan MWJ, Frier BM. The impact of diabetes on cognitive decline: potential vascular, metabolic, and psychosocial risk factors. Alzheimer's Research and Therapy. 2015;7(1):46.

7. Zhang H, Hao Y, Manor B, Zhang J, Fang J, Novak V, et al. Altered Resting-State Connectivity of Hippocampus with Default Mode Network In Type 2 Diabetes. Joint Annual Meeting ISMRM - ESMRMB; 2014.

8. Shemesh E, Rudich A, Harman-Boehm I, CukiermanYaffe T. Effect of intranasal insulin on cognitive function: a systematic review. The $\mathrm{J}$ of Clin Endocrinol and Metabol. 2012;97(2):366-76.

9. Brands AM, Biessels GJ, de Haan EH, Kappelle LJ, Kessels RP. The effects of type 1 diabetes on cognitive performance: a meta-analysis. Diabetes Care. 2005;28(3):726-35.

10. Messier C. Impact of impaired glucose tolerance and type 2 diabetes on cognitive aging. Neurobiol Aging. 2005;26 Suppl 1:26-30.

11. McCrimmon RJRC, Frier BM. Diabetes and cognitive dysfunction. Lancet. 2012;S0140-6736(1012):603602.

12. Tuma I. Diabetes mellitus and cognitive impairments. Vnitrni lekarstvi. 2007;53(5):486-8.

13. Kodl CT, Seaquist ER. Cognitive Dysfunction and Diabetes Mellitus. Endocrine Reviews. 2008;29(4):494-511.

14. Goldman E. How hyperglycemia drives cognitive dysfunction. Holistic primary care News for health and healing; 2013.

15. Brownlee M. The pathobiology of diabetic complications: a unifying mechanism. diabetes. 2005 Jun 1;54(6):1615-25.

Cite this article as: Patel DA, Patel DJ, Kantharia ND. A comparative study of impact on cognitive function between diabetic and non-diabetic patients in a tertiary care hospital. Int J Basic Clin Pharmacol 2018;7:1547-50. 